\title{
Review: Measures to control house dust mites are not effective in patients with asthma who are sensitive to mites
}

Gotzsche PC, Hammarquist $\mathrm{C}$, Burr $\mathrm{M}$. House dust mite control measures in the management of asthma: metaanalysis. BMJ. 1998 Oct 24;317: $1105-10$.

\section{Question}

Are measures to reduce exposure to dust-mite antigen in the home effective for patients with asthma who are sensitive to mites?

\section{Data sources}

Studies were identified by searching the Cochrane Airways Group database, which contains citations from MEDLINE, CINAHL, and EMBASE/ Excerpta Medica; hand searching Res piration (1980 to 1996) and Clinical and Experimental Allergy (1980 to 1996); and contacting primary authors.

\section{Study selection}

Stidies in any language were selected if they were randomised controlled trials that compared chemical or physical measures for controlling mites in the home with no treatment in patients with bronchial asthma. A diagnosis of asthma by a physician and confirmation of sensitisation to mites were required.

\section{Data extraction}

2 authors extracted data on subjective well-being, improvement in asthma symptoms, medication to control asthma, number of sick days, number of unscheduled visits to a physician or hospital, $F E V_{1}$, peak expiratory flow rate (PEFR), provocative concentration Commentary

This meta-analysis by Gorzsche and colleagues is suprising for 2 reasons: First, the results are contrary to logical reasoning-that reduced exposure to mites in mite-sensivive, asthmatic patients will cause the patients to improve. Second, the results conflict with a recent narrative review by Custovic and colleagues (1), which showed a slight benefit but also included uncontrolled studjes.

The evidence from this neta-analysis leads to the conclusion that house dust-mite control measures in the management of asthma are ineffective. This holds true for all outcome measures and for all subgroups (chemical

that caused a $20 \%$ decrease in $\mathrm{FEV}$, $\left(\mathrm{PC}_{20}\right)$, and restils of skin-prick testing.

\section{Main results}

22 studies met the inclusion criteria; 1 study had 3 groups and was treated as 2 trials in the meti-analysis ( 23 studies involving 686 adults and children). Follow up ranged from 2 weeks to 1 year (mean $19 \mathrm{wk}$ ). 13 studies used physical methods to control mites, with 3 report ing a reduction in mite exposure. 6 studies used chemical methods to control mites; none reported a reduction in mite exposure. 4 studies used a combination of methods, and only 3 reported a reduction in mite exposure. 5 studies did not assess mite exposure. No difference between groups existed in the number of patients who improved after intervention (5 studies), asthma symptom improvement (7 studies), PEFR in the morning (10 studies) of evening ( 6 studies), $\mathrm{PC}_{20}$, or medication use (Table). Heterogeneity existed among trials

Reduced dust-mite antigen vs no treatment in asthma*

\begin{tabular}{|c|c|c|c|c|}
\hline \multirow[t]{2}{*}{ Outcome (mean follown up) } & \multicolumn{2}{|c|}{ Weighted event rates } & \multirow[t]{2}{*}{$\mathrm{RBI}(95 \% \mathrm{CD})$} & \multirow[t]{2}{*}{ NNT } \\
\hline & Treated & Control & & \\
\hline Patients who improved (13 wk) & $37 \%$ & $32 \%$ & $11 \%(-20$ to 54$)$ & Not significant \\
\hline Outcomes (mean follow-up) & \multicolumn{4}{|c|}{ Standardised mean difference $(95 \% \mathrm{CI})$} \\
\hline Symptom improvement $(17 \mathrm{wk}$ & \multicolumn{4}{|c|}{$-0.06(-0.54$ to 0.41$)$} \\
\hline Peak expiratory fow a.m. (18 w & \multicolumn{4}{|c|}{$-0.03(-0.25$ to 0.19$)$} \\
\hline Peak expiratory flow p.m. (14 u & \multicolumn{4}{|c|}{$-0.13(-0.48$ to 0.22$)$} \\
\hline Provocative concentration (PC. & \multicolumn{4}{|c|}{$0.04(-0.32$ to 0.23$)$} \\
\hline Use of drugst & \multicolumn{4}{|c|}{$-0.14(-0.43$ to 0.15$)$} \\
\hline
\end{tabular}

*Abbreviations defined in Glossary; RBI, NNT, and Cl calculated from data in article $\dagger$ Follow-up data not reported.

methods, physical methods, and combinations). A more detailed look shows that the studies in which exposure to mites was reduced or not assessed did not produce more positive results than studies in which exposure to nites was not reduced. The ineffectiveness of this intervention is further supported by the consistency of the negative results, with no trend for benefit among subgroups.

For clinical practice, it can be concluded that house dust-mite control measures stadied so far are ineffective. Possible explanations (i.e., that initial mite exposure is already low in these patients and that compliance with the for asthma symptom improvemen $(P<0.001)$. When studies using chemi cal methods to control mite exposure were combined, PEFR in the morning was better for the control group that for the intervention group (standardised mean difference $-0.50,95 \%$ CT -0.98 to -0.01 ) .

\section{Conclusion}

Measures to reduce exposure to dustmite antigen in the home do not lead to an improvement in patients with asthma who are sensitive to mites.

Sources of funding: Nondic Conthil of Minnister Hovedstadens Sygebusfaellesskab, Rigshospitalef Denmatk; Sygekassemes Helsefond, Denmal Swedish Heat Lung Fondation.

For correspondence: Dr. P.C. Gotzsche, Nondi Cachnoue Centre, Rigshospitalet, Depantwent 7112 , DK 2200 Copenhagen $N$, Denmak FAX 45-3545-7007.

A modified version of this abstract appens in Evidence-Based Nursing. 1999 Jul. programme might be suboptimal) do nos change the conclusion of ineffectiveness in clinical practice.

Only large, randomised, controlled irits that assess both reduction in mite exposite and all relevant outcome measures $c_{2}$ change this conclusion.

$$
\begin{aligned}
& \text { Henrica C. de Vet, } \\
& \text { University of Math } \\
& \text { Maastricbt, The Netherlat }
\end{aligned}
$$

Reference

1. Custovic A, Simpson A, Chapman M $^{\text {D }}$ Woodcock A. Thorax, 1998;53:63-72

Evidence-Based Medicine Mav/[ang 1 /月) 